\title{
Structure, Reactivity, Photoactivity and Stability of Ti-O Based Materials: A Theoretical Comparison
}

\author{
Yun Wang, ${ }^{\mathrm{a}}$ Tao Sun, ${ }^{\mathrm{a}}$ Dongjiang Yang, ${ }^{\mathrm{a}}$ Hongwei Liu, ${ }^{\mathrm{a}}$ Haimin Zhang, ${ }^{\mathrm{a}}$ Xiangdong Yao ${ }^{\mathrm{b}}$ and Huijun \\ Zhao $^{* a}$
}

\author{
5 Received (in $X X X, X X X) X$ th $X X X X X X X X X 20 X X$, Accepted $X$ th $X X X X X X X X X 20 X X$ \\ DOI: $10.1039 / \mathrm{b000000x}$
}

Ti-O based materials have attracted great attention recently for their potential applications in clean energy generation and environment remediation. To screen Ti-O based materials for specific applications, the atomic-level understanding of the subtle discrepancy of their properties is of paramount importance. In 10 this regard, the density functional theory computations have been performed to systematically compare the physicochemical properties of three selected Ti-O based materials: anatase titanium dioxides, sodium trititanates and sodium hexatitanates. Due to their structure discrepancy, sodium trititanates show the highest chemical reactivity. However, titanium dioxides are found to be the most photoactive materials. The reactivity and photoactivity of sodium hexatitanates fall between those of titanium dioxide and 15 sodium trititanates. At the mean time, our energetic analysis also confirms that the thermal stabilities of Ti-O based materials are strongly dependent on the acid-base conditions. Titanium dioxides are preferred under acidic conditions, while titanates are more stable in basic solutions.

\section{Introduction}

Ti-O based materials are an important class of materials 20 comprised of $\mathrm{TiO}_{6}$ octahedra, which include titanium dioxides $\left(\mathrm{TiO}_{2}\right)$ and titanates. ${ }^{1-3}$ Traditionally, $\mathrm{TiO}_{2}$ is used as pigments; and titanates are well-known as functional ceramic materials. ${ }^{4}$ Recently, more advanced applications of Ti-O based materials have been proposed, such as catalysis, ${ }^{5-6}$ sensors, ${ }^{7}$ hydrogen 25 storage $^{8}$ lithium ion batteries, ${ }^{9}$ environmental remediation, ${ }^{10}$ absorption of radioactive ions in water treatment, ${ }^{11}$ electronics, ${ }^{12}$ solar cells ${ }^{13-15}$ and biomedicine. ${ }^{16}$ The applications in catalysis, hydrogen storage, water treatment and sensors are dependent on their chemical reactivities of materials. ${ }^{2}$ The efficiencies of Ti-O 30 based solar cells and photocatalysts are determined by their photoactivity. ${ }^{2}$ Meanwhile, their thermal stability is also crucial for their practical applications. Since the physicochemical properties of Ti-O based materials are strongly related to their atomic configurations, ${ }^{17-18}$ the understanding of the discrepancy 35 of the atomic configurations of Ti-O based materials and the corresponding structure-function relationship becomes essential for their development. However, based on our knowledge, there is no systematical comparison of the reactivity, photoactivity and thermal stability of Ti-O based materials. This comparison is

40

${ }^{a}$ Centre for Clean Environment and Energy, and Griffith School of Environment, Griffith University, Gold Coast, QLD 4222, Australia; Email:h.zhao@griffith.edu.au

${ }^{b}$ Queensland Micro- and Nanotechnology Centre, Nathan Campus, 45 Griffith University, QLD 4111, Australia therefore dedicated in this study based on density-functional theory (DFT) calculations. DFT is employed because it is the most popular quantum chemistry method which reduces the computation consumption sharply with chemistry accuracy. ${ }^{19}$

$50 \mathrm{Up}$ to date numerous Ti-O based materials have been discovered or synthesized. It is impossible to compare the properties of all Ti-O based materials. Representative Ti-O based materials are hence screened in this study. Firstly, anatase $\mathrm{TiO}_{2}$ phase is chosen since the previous experimental and theoretical ${ }_{55}$ studies have demonstrated that anatase is the most active $\mathrm{TiO}_{2}$ phase. ${ }^{1,20}$ Meanwhile, sodium titanates $\left(\mathrm{Na}_{2} \mathrm{Ti}_{n} \mathrm{O}_{2 n+1}\right)$ are selected because they are widely employed in many practical applications. $^{2-3}$ In general, titanates with higher sodium content possess layered structures, while the titanates with lower sodium 60 content have tunnelled structures. Among them, sodium trititanates $\left(\mathrm{Na}_{2} \mathrm{Ti}_{3} \mathrm{O}_{7}\right)$ are the best studied titanates with a layered structure ${ }^{21}$ and sodium hexatitanates $\left(\mathrm{Na}_{2} \mathrm{Ti}_{6} \mathrm{O}_{13}\right)$ are the most widely used titanates with a tunnelled structure. ${ }^{22}$ Based on these considerations, anatase $\mathrm{TiO}_{2}, \mathrm{Na}_{2} \mathrm{Ti}_{3} \mathrm{O}_{7}$ and $\mathrm{Na}_{2} \mathrm{Ti}_{6} \mathrm{O}_{13}$ are ${ }_{65}$ deliberately selected in this study. The structures of three Ti-O based materials are shown in Fig. 1.

The DFT studies focusing on anatase $\mathrm{TiO}_{2}$ have been comprehensively performed previously. ${ }^{20}$ And recently, the structural and electronic properties of $\mathrm{Na}_{2} \mathrm{Ti}_{3} \mathrm{O}_{7}$ were also 70 investigated. ${ }^{23-25}$ However, there is no theoretical analysis on the physicochemical properties of titanates with a tunnelled structure. In this regard, the structural and electronic properties of $\mathrm{Na}_{2} \mathrm{Ti}_{6} \mathrm{O}_{13}$ are firstly investigated in this study. Then, the structural discrepancy of three Ti-O based materials is analyzed 
by using our DFT optimized atomic structures. After that, their chemical reactivity and photoactivity are compared according to their electronic structures. Finally, the thermal stability of three Ti-O based materials is compared based on the energetic data.

\section{${ }_{5}$ 2. Computation Details}

All DFT computations are performed using the Quantum Espresso (QE) package. ${ }^{26}$ Electron-ion interactions are described using the Vanderbilt-type ultrasoft pseudopotentials. ${ }^{27}$ Valence states include the $\mathrm{Ti} 4 s, 4 p, 3 d$, and $4 s$ states, the $\mathrm{O} 2 s$ and $2 p$ 10 states, and the $\mathrm{Na} 3 s$ states. A plane-wave basis set was used with the cut-off kinetic energy as $30 \mathrm{Ry}$. For the electron-electron exchange and correlation interactions, the functional of Perdew, Burke and Ernzerhof (PBE), ${ }^{28}$ a form of the general gradient approximation (GGA), is used throughout. When the geometry is 15 optimized, all atoms are allowed to relax. Since there are four structure parameters to determine the optimized lattice of the bulk systems of sodium titanates, to obtain the theoretical values of these parameters through traditional DFT calculations is quite time-consuming. Thus, the variable cell technique is employed to 20 optimize these parameters. We perform Brillouin-zone integrations using Monkhorst-Pack grids of special points with a $(4 \times 4 \times 2),(1 \times 4 \times 2)$ or $(2 \times 4 \times 2)$ mesh for anatase $\mathrm{TiO}_{2}, \mathrm{Na}_{2} \mathrm{Ti}_{6} \mathrm{O}_{13}$ or $\mathrm{Na}_{2} \mathrm{Ti}_{3} \mathrm{O}_{7}$, respectively. The supercell of anatase $\mathrm{TiO}_{2}$, $\mathrm{Na}_{2} \mathrm{Ti}_{6} \mathrm{O}_{13}$ or $\mathrm{Na}_{2} \mathrm{Ti}_{3} \mathrm{O}_{7}$ includes 12,42 or 24 atoms, respectively.

${ }_{25}$ The selected k-mesh densities and the cut-off kinetic energy have been justified in our previous studies. ${ }^{17,25,29}$ In the analysis of the thermal stabilities of three Ti-O based materials, the reaction energies between Ti-O based materials and isolated acidic or basic molecules are calculated. Even though experimental results 30 for these reactions have been obtained in aqueous solution, ${ }^{30-32}$ the calculations incorporating the solution effect will be unaffordable in terms of computation cost. Therefore a practical approach is to employ energies of average unit of crystals or isolated molecules for the thermal stability analysis since they are

35 the major reactants and products. In this study, isolated molecules are in the cubic supercell with the lattice constant of $15 \AA$ in calculations with the gamma-point only mesh. And the energy of the $\mathrm{NaCl}$ unit cell is calculated by using a $(16 \times 16 \times 16) \mathrm{k}$-point mesh.

\section{${ }_{40}$ 3. Results and discussion}

\subsection{Structural and electronic properties of $\mathrm{Na}_{2} \mathrm{Ti}_{6} \mathrm{O}_{13}$}

$\mathrm{Na}_{2} \mathrm{Ti}_{6} \mathrm{O}_{13}$ was once used as a good supporter of photocatalysts for water splitting by Inoue and his co-workers. ${ }^{33}$ Then, the $\mathrm{Na}_{2} \mathrm{Ti}_{6} \mathrm{O}_{13}$ nanobelts themselves were found to exhibit 45 good photocatalytic efficiency for the decomposition of organic pollutants in water under ultraviolet irradiation. ${ }^{34}$ Meanwhile, they can also be used as the precursor to produce the important dielectric, ferroelectric, piezoelectric and electrostrictive material: barium titanates. ${ }^{35}$ Recently, it was found that $\mathrm{Na}_{2} \mathrm{Ti}_{6} \mathrm{O}_{13}$ was a 50 good candidate to be used as anode materials of lithium ion batteries since it owns a low voltage range for the reversible insertion of lithium ions. ${ }^{36-37}$ Due to their tunnelled structures, $\mathrm{Na}_{2} \mathrm{Ti}_{6} \mathrm{O}_{13}$ nanofibers have also been found to have potential to selectively absorb radioactive ions from water. ${ }^{31}$ However, most 55 of the previous studies on $\mathrm{Na}_{2} \mathrm{Ti}_{6} \mathrm{O}_{13}$ materials focused on the synthesis techniques and their applications. ${ }^{22,34,38-42}$ To the best of our knowledge, there is no theoretical study on the structural and electronic properties of $\mathrm{Na}_{2} \mathrm{Ti}_{6} \mathrm{O}_{13}$ materials. To compare the properties of selected Ti-O based materials, this theoretical study ${ }_{60}$ is therefore dedicated to investigate physicochemical properties of $\mathrm{Na}_{2} \mathrm{Ti}_{6} \mathrm{O}_{13}$ materials firstly.
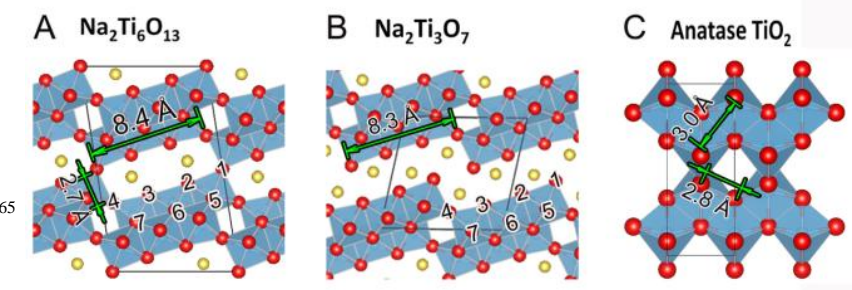

Fig. 1 The atomic configurations of (A) $\mathrm{Na}_{2} \mathrm{Ti}_{6} \mathrm{O}_{13}$ with a tunnel structure, (B) $\mathrm{Na}_{2} \mathrm{Ti}_{3} \mathrm{O}_{7}$, and (C) anatase $\mathrm{TiO}_{2}$, with a layered structure. The black frame represents the size of a unit cell. Blue octahedron-[ $\left.\mathrm{TiO}_{6}\right]$, yellow70 Sodium, red-oxygen, and blue-titanium.

The structure of $\mathrm{Na}_{2} \mathrm{Ti}_{6} \mathrm{O}_{13}$ was determined by Torres-Martínez et al. by a Rietveld refinement to simulate the experimental X-ray powder diffraction (XRD) patterns. ${ }^{39}$ It is found that the $\mathrm{Na}_{2} \mathrm{Ti}_{6} \mathrm{O}_{13}$ crystal is a monoclinic cell with space group $\mathrm{C} 2 / \mathrm{m}^{39}$ ${ }_{75}$ Fig. 1A shows the optimized structure of a $\mathrm{Na}_{2} \mathrm{Ti}_{6} \mathrm{O}_{13}$ crystal, and the lattice constants for a fully relaxed $\mathrm{Na}_{2} \mathrm{Ti}_{6} \mathrm{O}_{13}$ structure, which are compared with the experimental values of Torres-Martínez et al., are listed in Table 1. Our theoretical volume is about $1.6 \%$ larger than those from the experiments. Such discrepancy is 80 ascribed to the approximation of GGA-DFT. ${ }^{43}$ The atomic positions of $\mathrm{Na}_{2} \mathrm{Ti}_{6} \mathrm{O}_{13}$ compared with the experimental data of Torres-Martínez et al. are listed in Table 2. After fully optimization, our theoretical fractional atomic coordinates are in agreement with the experimental observations greatly. The Ti-O 85 bond length is with the range of $1.76 \AA$ to $2.27 \AA$, which are also similar to those reported by Torres-Martínez et al.. ${ }^{39}$

Table 1 The theoretical lattice constants of $\mathrm{Na}_{2} \mathrm{Ti}_{6} \mathrm{O}_{13}$ in comparison with 90 the experimental data ${ }^{39}$.

\begin{tabular}{|c|c|c|}
\hline & theoretical & experiment \\
\hline $\mathrm{a}(\AA ̊)$ & 15.21 & 15.10 \\
\hline b $(\AA)$ & 3.75 & 3.75 \\
\hline c $(\AA)$ & 9.25 & 9.17 \\
\hline$\beta\left(^{\circ}\right)$ & 98.9 & 99.0 \\
\hline $\mathrm{V}\left(\AA^{3}\right)$ & 520.8 & 512.3 \\
\hline
\end{tabular}

Table 2. The theoretical fractional atomic coordinates of $\mathrm{Na}_{2} \mathrm{Ti}_{6} \mathrm{O}_{13}$ in comparison with the experimental data ${ }^{39}$. The number of the oxygen atoms is defined in Fig. 1B.

\begin{tabular}{|c|c|c|c|c|}
\hline & $\begin{array}{c}\mathrm{x} \\
\text { (theoretical) }\end{array}$ & $\begin{array}{c}\mathrm{x} \\
\text { (experiment) }\end{array}$ & $\begin{array}{c}\mathrm{z} \\
\text { (theoretical) }\end{array}$ & $\begin{array}{c}\mathrm{Z} \\
\text { (experiment) }\end{array}$ \\
\hline $\mathrm{Na} 1$ & 0.46203 & 0.46102 & 0.26975 & 0.26595 \\
\hline Ti1 & 0.11455 & 0.11311 & 0.09562 & 0.09740 \\
\hline $\mathrm{Ti} 2$ & 0.16538 & 0.16716 & 0.43592 & 0.43740 \\
\hline Ti3 & 0.22718 & 0.22689 & 0.77015 & 0.77019 \\
\hline O1 & -0.00002 & 0.00000 & 0.00000 & 0.00000 \\
\hline $\mathrm{O} 2$ & 0.06974 & 0.07020 & 0.29281 & 0.29497 \\
\hline $\mathrm{O} 3$ & 0.12649 & 0.12873 & 0.61489 & 0.61793 \\
\hline $\mathrm{O} 4$ & 0.16298 & 0.16904 & 0.91327 & 0.91716 \\
\hline O5 & 0.35657 & 0.35786 & 0.88228 & 0.88499 \\
\hline O6 & 0.29798 & 0.30113 & 0.57055 & 0.57074 \\
\hline $\mathrm{O} 7$ & 0.24065 & 0.23769 & 0.24576 & 0.24064 \\
\hline
\end{tabular}

95 


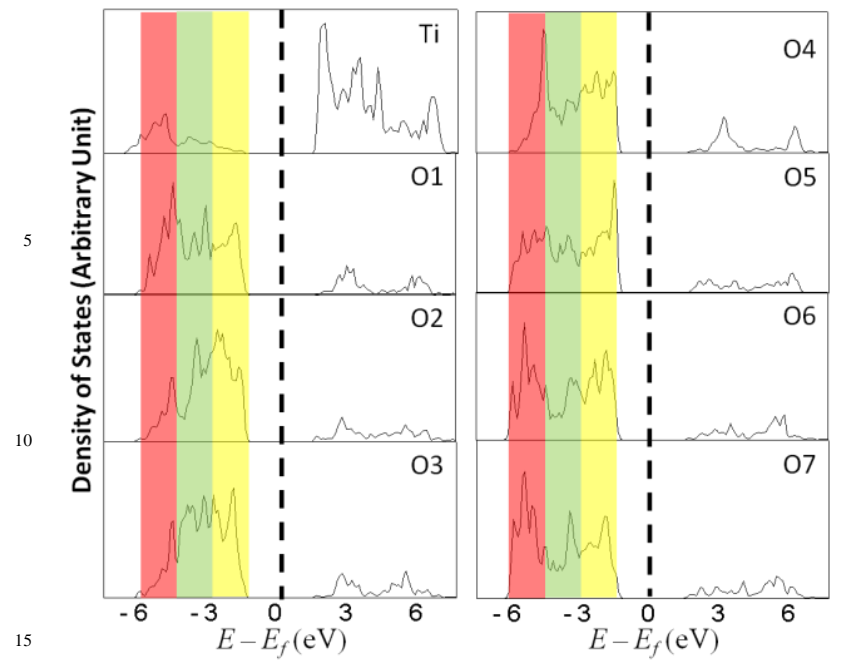

Fig. 2 Partial density of states of a titanium atom and seven distinctive oxygen atoms in $\mathrm{Na}_{2} \mathrm{Ti}_{6} \mathrm{O}_{13}$. The number of the oxygen atoms is defined in Fig. 1A. The dashed line is the location of Fermi energy $\left(E_{f}\right)$. The red area is low-energy range $\left(-6.0 \mathrm{eV}<E-E_{\mathrm{f}}<-4.5 \mathrm{eV}\right)$; the green area is the 20 intermediate-energy range $\left(-4.5 \mathrm{eV}<E-E_{f}<-3.0 \mathrm{eV}\right)$; and the yellow area is the high-energy range $\left(-3.0 \mathrm{eV}<E-E_{f}<-1.5 \mathrm{eV}\right)$.

Recently, the layered $\mathrm{Na}_{2} \mathrm{Ti}_{3} \mathrm{O}_{7}$ materials have been found that the lattice oxygen atoms show much diverse reactivity experimentally when the radioactive ions are absorbed by ${ }_{25} \mathrm{Na}_{2} \mathrm{Ti}_{3} \mathrm{O}_{7}{ }^{44-45}$ The theoretical DFT calculations have revealed that the diverse reactivity is originated from the electronic properties of lattice oxygen atoms, which are determined by their chemical environments. ${ }^{25}$ While $\mathrm{Na}_{2} \mathrm{Ti}_{6} \mathrm{O}_{13}$ shows a various structure comparing with $\mathrm{Na}_{2} \mathrm{Ti}_{3} \mathrm{O}_{7}$, the lattice oxygen atoms of ${ }_{30} \mathrm{Na}_{2} \mathrm{Ti}_{6} \mathrm{O}_{13}$ also face various chemical environments, as shown in Fig. 1A. Since the diverse reactivity of lattice oxygen atoms in $\mathrm{Na}_{2} \mathrm{Ti}_{3} \mathrm{O}_{7}$ has been found to play important role in their applications, ${ }^{31,44}$ the similar diverse reactivity should be also expected to affect the applications of $\mathrm{Na}_{2} \mathrm{Ti}_{6} \mathrm{O}_{13}$ materials.

35 To analyze the electronic properties of $\mathrm{Na}_{2} \mathrm{Ti}_{6} \mathrm{O}_{13}$ materials, the partial density of states (PDOS) of each distinctive atom are calculated. Since each $\mathrm{Ti}$ atom is surrounded by six $\mathrm{O}$ atoms to form a $\mathrm{TiO}_{6}$ octahedron, the chemical environments of all $\mathrm{Ti}$ atoms are similar. By contrast, the distinctive $\mathrm{O}$ atoms confront 40 much different surroundings. The coordination number is two for $\mathrm{O} 1, \mathrm{O} 2, \mathrm{O} 3$ and $\mathrm{O} 4$, three for $\mathrm{O} 5$, and four for $\mathrm{O} 6$ and $\mathrm{O} 7$ in the $\mathrm{TiO}_{6}$ octahedra, respectively. The number of $\mathrm{O}$ atoms is denoted in Fig. 1A. The PDOS images suggest that $\mathrm{O} 1-\mathrm{O} 4$ atoms are more active than O5-O7. As shown in Fig. 2, the peaks of O- $2 p$ 45 states are divided into three classes: $-6.0 \mathrm{eV}<E-E_{f}<-4.5 \mathrm{eV}$ (red, low-energy range), $-4.5 \mathrm{eV}<E-E_{f}<-3.0 \mathrm{eV}$ (green, intermediate-energy range), and $-3.0 \mathrm{eV}<E-E_{f}<-1.5 \mathrm{eV}$ (yellow, high-energy range). The denser states of atoms at highenergy range indicate the higher reactivity. From Fig. 2, the main 50 peaks of O1-O4 $2 p$ states locate at the high- and intermediateenergy ranges. With the increase of the coordination number of $\mathrm{O}$ atoms, the main peaks shift from the high-energy area to the lowenergy area. For O6 and O7 atoms, their main peaks all fall within the low-energy ranges. The PDOS shifted from high-

55 energy area to the low-energy area indicates a decreased reactivity for oxygen atoms. Thus, it demonstrates that the coordination number of $\mathrm{O}$ atoms is the dominate factor for their reactivity. This conclusion is in agreement with the previous theoretical analysis on $\mathrm{Na}_{2} \mathrm{Ti}_{3} \mathrm{O}_{7} \cdot{ }^{25}$

\section{${ }_{60}$ 3.2 Structure discrepancy of Ti-O based materials}

The most obvious difference of the three Ti-O based materials is their atomic structures, as shown in Fig. 1. Anatase $\mathrm{TiO}_{2}$ is a materials with a small rhombus tunnel along $\langle 010\rangle$ direction. The tunnel side length is about 3.0 $\AA$. Meanwhile, both $\mathrm{Na}_{2} \mathrm{Ti}_{3} \mathrm{O}_{7}$ 65 and $\mathrm{Na}_{2} \mathrm{Ti}_{6} \mathrm{O}_{13}$ are monoclinic. $\mathrm{Na}_{2} \mathrm{Ti}_{3} \mathrm{O}_{7}$ shows a layered structure. And $\mathrm{Na}$ ions are located in the space between $\mathrm{Ti}-\mathrm{O}$ layers. On the other hand, $\mathrm{Na}_{2} \mathrm{Ti}_{6} \mathrm{O}_{13}$ is with a typical tunnelled structure. There are two different sizes of tunnels: the big one is an $8.4 \AA \times 2.7 \AA$ rectangle, which accommodates two Na atoms in 70 each tunnel; and the small rhombus one is similar as that of anatase $\mathrm{TiO}_{2}$. The different morphology is expected to affect their application greatly. Firstly, sodium titanates show exclusive ionexchange properties due to sodium ions between $\mathrm{TiO}_{6}$ octahedra can be replaced by protons or other transition-metal ions. ${ }^{46}$ 75 Secondly, layered $\mathrm{Na}_{2} \mathrm{Ti}_{3} \mathrm{O}_{7}$ has the highest internal surface area, which will benefit the absorption of radioactive metal wastes. ${ }^{44-45}$ Thirdly, the specific tunnelled structure of $\mathrm{Na}_{2} \mathrm{Ti}_{6} \mathrm{O}_{13}$ gives its promising for applications in ion conductivity, or electron conductivity. So, $\mathrm{Na}_{2} \mathrm{Ti}_{6} \mathrm{O}_{13}$ is a good candidate in lithium ion 80 battery. $^{36}$

Another structure discrepancy of three Ti-O based materials is the coordination number of lattice oxygen atoms. Since Ti atoms locate at the centre of $\mathrm{TiO}_{6}$ octahedra in anatase $\mathrm{TiO}_{2}, \mathrm{Na}_{2} \mathrm{Ti}_{6} \mathrm{O}_{13}$, and $\mathrm{Na}_{2} \mathrm{Ti}_{3} \mathrm{O}_{7}$, all their coordination numbers are six. However, 85 the coordination numbers of distinctive lattice oxygen atoms are different. The coordination number is determined by the number of $\mathrm{TiO}_{6}$ octahedra sharing the same oxygen atom. In anatase $\mathrm{TiO}_{2}$, all the lattice oxygen is chemical identical due to their high symmetry with the coordination number as three. However, there 90 are seven distinctive oxygen atoms in $\mathrm{Na}_{2} \mathrm{Ti}_{6} \mathrm{O}_{13}$ and $\mathrm{Na}_{2} \mathrm{Ti}_{3} \mathrm{O}_{7}$. The seven distinctive $\mathrm{O}$ atoms have been marked as $\mathrm{O} 1-\mathrm{O} 7$, as shown in Fig. 1. In $\mathrm{Na}_{2} \mathrm{Ti}_{6} \mathrm{O}_{13}$, each $\mathrm{O} 1, \mathrm{O} 2, \mathrm{O} 3$ or $\mathrm{O} 4$ atom bonds to two Ti atoms. As a comparison, each $\mathrm{O} 5$ atom interacts with three $\mathrm{Ti}$ atoms; and each $\mathrm{O} 6$ or $\mathrm{O} 7$ atom connects with four ${ }_{95} \mathrm{Ti}$ atoms in the $\mathrm{TiO}_{6}$ octahedra. In $\mathrm{Na}_{2} \mathrm{Ti}_{3} \mathrm{O}_{7}$, the coordination number of $\mathrm{O}$ atoms is slightly different. The coordination number of $\mathrm{O} 1$ of $\mathrm{Na}_{2} \mathrm{Ti}_{3} \mathrm{O}_{7}$ is merely one. And the coordination numbers of other lattice oxygen atoms are same as those in $\mathrm{Na}_{2} \mathrm{Ti}_{6} \mathrm{O}_{13}$. Since the coordination number of lattice oxygen is the decisive 100 factor to their electronic properties and reactivity, ${ }^{25}$ the chemical properties of these Ti-O based materials are expected to be much diverse. The comparison about the reactivity of these materials will be discussed below.

\subsection{Reactivity of Ti-O based materials}

105 The chemical reactivity of Ti-O based materials is important to their applications in sensors, catalysis, absorption, and hydrogen storage. The previous theoretical studies have demonstrated that the reactivities of the lattice oxygen atoms in titanates are determined by their electronic properties. ${ }^{25}$ Thus, the electronic 110 properties of lattice oxygen atoms of three Ti-O based materials are compared based on their PDOS. The PDOS of the lattice oxygen atoms with the highest reactivity of the three Ti-O based materials are shown in Fig. 3. The PDOS peaks of $\mathrm{Na}_{2} \mathrm{Ti}_{3} \mathrm{O}_{7}$ in the low-energy range (marked as the red area in Fig. 3) are the 
lowest. And the peaks of $\mathrm{TiO}_{2}$ in the low-energy range are the highest. On the other side, the PDOS peaks of the $\mathrm{O} 1$ atoms of $\mathrm{Na}_{2} \mathrm{Ti}_{3} \mathrm{O}_{7}$ at the high-energy range (marked as the yellow area in Fig. 3) are the highest. The different shapes of the PDOS images s indicate that $\mathrm{Na}_{2} \mathrm{Ti}_{3} \mathrm{O}_{7}$ shows the highest chemical reactivity while anatase $\mathrm{TiO}_{2}$ is the most chemically inert materials among them. This conclusion is supported by experiments of Yang et al. that $\mathrm{Na}_{2} \mathrm{Ti}_{6} \mathrm{O}_{13}$ nanofibers have a lower ion-exchange capacity comparing with that for $\mathrm{Na}_{2} \mathrm{Ti}_{3} \mathrm{O}_{7}$ nanofibers. ${ }^{9}$

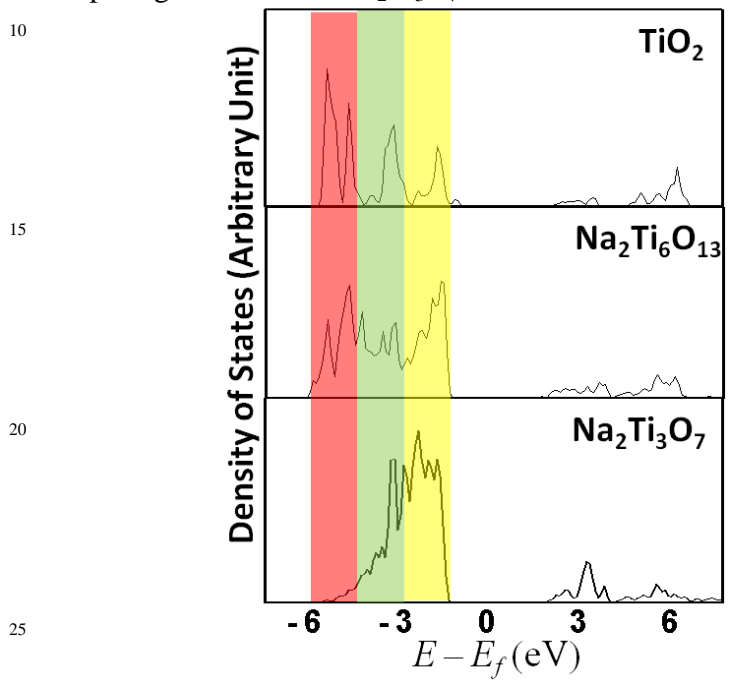

Fig. 3 Partial density of states of the most reactive lattice $\mathrm{O}$ atom of the three Ti-O based materials: anatase $\mathrm{TiO}_{2}, \mathrm{Na}_{2} \mathrm{Ti}_{3} \mathrm{O}_{7}$ and $\mathrm{Na}_{2} \mathrm{Ti}_{6} \mathrm{O}_{13}$. The red area is low-energy range $\left(-6.0 \mathrm{eV}<E-E_{\mathrm{f}}<-4.5 \mathrm{eV}\right)$; the green area is 30 the intermediate-energy range $\left(-4.5 \mathrm{eV}<E-E_{f}<-3.0 \mathrm{eV}\right)$; and the yellow area is the high-energy range $\left(-3.0 \mathrm{eV}<E-E_{f}<-1.5 \mathrm{eV}\right)$

The difference of reactivity can be explained according to their structural properties. In the analysis of the reactivity of lattice oxygen atoms in $\mathrm{Na}_{2} \mathrm{Ti}_{6} \mathrm{O}_{13}$ and $\mathrm{Na}_{2} \mathrm{Ti}_{3} \mathrm{O}_{7}$, lattice oxygen atoms 35 with a smaller coordination number are reactivite. ${ }^{25}$ Based on the discussion of the structure discrepancy of three Ti-O based materials, the coordination numbers of the most reactive oxygen atoms in different materials vary. In $\mathrm{Na}_{2} \mathrm{Ti}_{3} \mathrm{O}_{7}$, the lattice $\mathrm{O} 1$ atoms bond to merely one $\mathrm{Ti}$ atom in $\mathrm{TiO}_{6}$ octahedra. ${ }^{25,} 45$ 40 However, in $\mathrm{Na}_{2} \mathrm{Ti}_{6} \mathrm{O}_{13}$, the lowest coordination number for $\mathrm{O}$ atoms is two. And the coordination number of lattice oxygen in anatase $\mathrm{TiO}_{2}$ is three. As a result, the $\mathrm{Na}_{2} \mathrm{Ti}_{3} \mathrm{O}_{7}$ shows the highest reactivity among three $\mathrm{Ti}-\mathrm{O}$ based materials.

\subsection{Photoactivity of Ti-O based materials}

45 Since all three Ti-O based materials have been proposed to the applications in photocatalysis, ${ }^{21,39,47}$ the understanding of their photoactivity is crucial for their further development. From the analysis of PDOS, as shown in Fig. 2 and previous literatures, ${ }^{25}$, 48 it is found that the contribution to the bands around Fermi 50 energy level is similar for all Ti-O based materials. Most of the DOS of O- $2 p$ states locate at the highest valence bands (VB). As a comparison, the major composite of lowest conduction bands (CB) is Ti-3d states. The similar electronic structures of Ti-O based materials explain why all of them can be used as 55 photocatalysts. Furthermore, their similar electronic structures also suggest that the photo-excitation mechanism based on $\mathrm{TiO}_{2}$ photocatalysts can also be used for titanates.

To compare the photoactivity of three Ti-O based materials, their bandgap energies $\left(E_{g}\right)$ are calculated since $E_{g}$ determines the 60 efficiency of the visible sunlight absorption. Although the traditional DFT method underestimates the real $E_{g}$ of semiconductors seriously, ${ }^{49-50}$ the previous theoretical studies have demonstrated that the DFT results can be used to get the optical properties of materials qualitatively. ${ }^{51}$ Based on our 65 calculations, it is found that the $E_{g}$ of sodium titanates are much higher than that of $\mathrm{TiO}_{2}$ (the $E_{g}$ is $2.14 \mathrm{eV}, 3.03 \mathrm{eV}$ and $3.09 \mathrm{eV}$

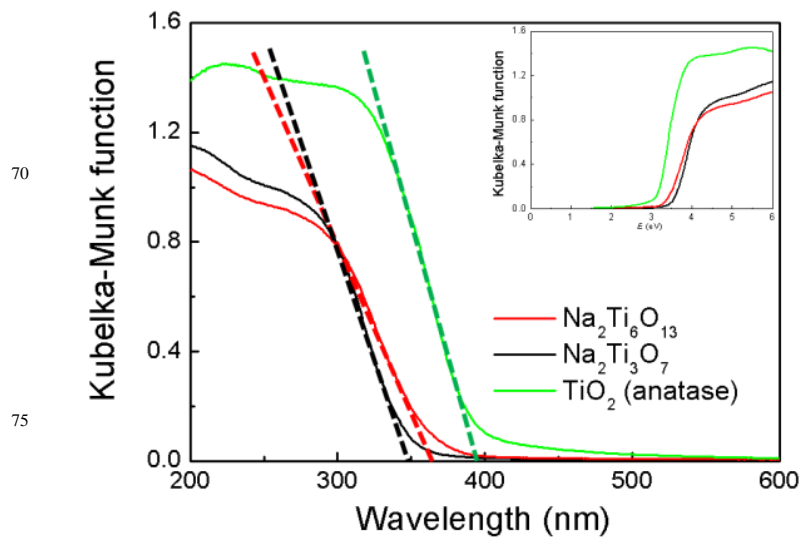

Fig. $4 \mathrm{UV}$-vis absorption spectra obtained from anatase $\mathrm{TiO}_{2}, \mathrm{Na}_{2} \mathrm{Ti}_{6} \mathrm{O}_{13}$, and $\mathrm{Na}_{2} \mathrm{Ti}_{3} \mathrm{O}_{7}$ nanofibers. The insert is the plot of Kubelka-Munk function 80 vs. the energy of light.

for anatase $\mathrm{TiO}_{2}, \mathrm{Na}_{2} \mathrm{Ti}_{6} \mathrm{O}_{13}$ and $\mathrm{Na}_{2} \mathrm{Ti}_{3} \mathrm{O}_{7}$, respectively). It indicates that the corresponding photoactivity of titanates is lower than that of $\mathrm{TiO}_{2}$. To evaluate our theoretical prediction, we have investigated the UV-vis diffusion reflectance (UV-vis DR) 85 spectra of $\mathrm{Na}_{2} \mathrm{Ti}_{3} \mathrm{O}_{7}, \mathrm{Na}_{2} \mathrm{Ti}_{6} \mathrm{O}_{13}$, and anatase $\mathrm{TiO}_{2}$ nanofibers. The results are displayed in Fig. 4. All the materials are prepared by the hydrothermal method under the same conditions used in the previous experiments. ${ }^{44-45}$ The onset wavelength $\lambda_{\text {onse }}$ of the spectrum recorded from $\mathrm{Na}_{2} \mathrm{Ti}_{3} \mathrm{O}_{7}, \mathrm{Na}_{2} \mathrm{Ti}_{6} \mathrm{O}_{13}$ or anatase $\mathrm{TiO}_{2}$ is 90 $350 \mathrm{~nm}(3.54 \mathrm{eV}), 360 \mathrm{~nm}(3.44 \mathrm{eV})$ and $400 \mathrm{~nm}(3.10 \mathrm{eV}) \mathrm{nm}$, respectively. Our UV-Vis diffusion reflectance spectra data for anatase $\mathrm{TiO}_{2}$ and $\mathrm{Na}_{2} \mathrm{Ti}_{3} \mathrm{O}_{7}$ are in agreement with the previous experimental data. ${ }^{52-53}$ Apparently, the experimental $E_{g}$ data support the theoretical prediction that sodium titanates can only 95 absorb UV light with shorter wavelength. To increase the photoactivity of titanates under visible sunlight, further bandgap engineering is required.

\subsection{Thermal stability of Ti-O based materials}

In the experiments, sodium titanates can be produced through 100 the interaction between $\mathrm{TiO}_{2}$ and $\mathrm{NaOH} .{ }^{21-22,} 32$ Thus, we have calculated the formation energy of sodium titanates according to the equation:

$$
\begin{aligned}
& 6 \mathrm{TiO}_{2}+2 \mathrm{NaOH}=\mathrm{Na}_{2} \mathrm{Ti}_{6} \mathrm{O}_{13}+\mathrm{H}_{2} \mathrm{O} \\
& \text { or } \\
& 1053 \mathrm{TiO}_{2}+2 \mathrm{NaOH}=\mathrm{Na}_{2} \mathrm{Ti}_{3} \mathrm{O}_{7}+\mathrm{H}_{2} \mathrm{O}
\end{aligned}
$$

Both reaction energies are negative: $-4.94 \mathrm{eV}$ and $-5.20 \mathrm{eV}$ for the formation energies of $\mathrm{Na}_{2} \mathrm{Ti}_{3} \mathrm{O}_{7}$ and $\mathrm{Na}_{2} \mathrm{Ti}_{6} \mathrm{O}_{13}$, respectively, which means that the reactions are energetically preferred. The recent XRD and SEM images have demonstrated that the sodium 110 titanates are the more stable phase when the Ti-O nanocrystals are synthesized through hydrothermal methods under basic conditions. $^{32}$ Our theoretical conclusions hence confirm the 
experimental observation. ${ }^{21-22,32}$

The sodium titanates can also change into $\mathrm{TiO}_{2}$ systems by interacting with acid, such as $\mathrm{HCl}^{32}$ The overall reaction can be written as:

${ }_{5} \mathrm{Na}_{2} \mathrm{Ti}_{6} \mathrm{O}_{13}+2 \mathrm{HCl}=6 \mathrm{TiO}_{2}+2 \mathrm{NaCl}+\mathrm{H}_{2} \mathrm{O}$

or

$\mathrm{Na}_{2} \mathrm{Ti}_{3} \mathrm{O}_{7}+2 \mathrm{HCl}=3 \mathrm{TiO}_{2}+2 \mathrm{NaCl}+\mathrm{H}_{2} \mathrm{O}$

The reaction energy is $-1.94 \mathrm{eV}$ and $-2.19 \mathrm{eV}$ for $\mathrm{Na}_{2} \mathrm{Ti}_{6} \mathrm{O}_{13}$ and $\mathrm{Na}_{2} \mathrm{Ti}_{3} \mathrm{O}_{7}$, respectively. Our theoretical data support that the $\mathrm{TiO}_{2}$ 10 is more stable under acidic conditions. Thus, the thermal stability of Ti-O based materials strongly dependent on the acid-base conditions in the synthesis process. Meanwhile, the reverse reaction of (1)-(4) can be used to describe the reaction of $\mathrm{TiO}_{2}$ or sodium titanates under the $\mathrm{pH}$-neutral condition. Based on our 15 theoretical results, all the reverse reactions are endothermic, which suggests that all Ti-O based materials are stable under $\mathrm{pH}$ neutral solutions.

To compare the thermal stability of $\mathrm{Na}_{2} \mathrm{Ti}_{3} \mathrm{O}_{7}$ and $\mathrm{Na}_{2} \mathrm{Ti}_{6} \mathrm{O}_{13}$, we have calculated the reaction energy of the two phase change, 20 as proposed according to the recent Raman spectra: ${ }^{30}$

$2 \mathrm{Na}_{2} \mathrm{Ti}_{3} \mathrm{O}_{7}+\mathrm{H}_{2} \mathrm{O}=\mathrm{Na}_{2} \mathrm{Ti}_{6} \mathrm{O}_{13}+2 \mathrm{NaOH}$

Based on our calculations, the reaction energy is positive: 9.35 $\mathrm{eV}$, which indicates that the above reaction is not energetically favourable. This is contrary to the experimental observation that ${ }_{25} \mathrm{Na}_{2} \mathrm{Ti}_{3} \mathrm{O}_{7}$ can be converted into $\mathrm{Na}_{2} \mathrm{Ti}_{6} \mathrm{O}_{13}$ at high temperature. ${ }^{30}$ The theory-experiment discrepancy can be explained by considering the phase transformation condition from $\mathrm{Na}_{2} \mathrm{Ti}_{3} \mathrm{O}_{7}$ to $\mathrm{Na}_{2} \mathrm{Ti}_{6} \mathrm{O}_{13}$. In the experiment, $\mathrm{Na}_{2} \mathrm{Ti}_{6} \mathrm{O}_{13}$ is produced by calcinating $\mathrm{Na}_{2} \mathrm{Ti}_{3} \mathrm{O}_{7}$ at $300^{\circ} \mathrm{C}$ under air flow. ${ }^{30}$ Since $\mathrm{H}_{2} \mathrm{O}$ is 30 continuously supplied and the $\mathrm{NaOH}$ is blowed away by air flow, the reaction (5) can hence dynamically occur. Once $\mathrm{Na}_{2} \mathrm{Ti}_{6} \mathrm{O}_{13}$ interacts with the basic solution, it should be changed back into $\mathrm{Na}_{2} \mathrm{Ti}_{3} \mathrm{O}_{7}$ based on our theoretical prediction. Indeed, Morgado and his co-workers demonstrated that the $\mathrm{Na}_{2} \mathrm{Ti}_{3} \mathrm{O}_{7}$ crystal is the 35 most stable phase for sodium titanates at the basic condition. ${ }^{54}$

Meanwhile, the phase change from $\mathrm{Na}_{2} \mathrm{Ti}_{3} \mathrm{O}_{7}$ to $\mathrm{Na}_{2} \mathrm{Ti}_{6} \mathrm{O}_{13}$ under the acidic condition is also considered:

$2 \mathrm{Na}_{2} \mathrm{Ti}_{3} \mathrm{O}_{7}+2 \mathrm{HCl}=\mathrm{Na}_{2} \mathrm{Ti}_{6} \mathrm{O}_{13}+2 \mathrm{NaCl}+\mathrm{H}_{2} \mathrm{O}$

The calculated reaction energy is $-2.46 \mathrm{eV}$, which suggests that 40 the $\mathrm{Na}_{2} \mathrm{Ti}_{3} \mathrm{O}_{7}$ can be converted to $\mathrm{Na}_{2} \mathrm{Ti}_{6} \mathrm{O}_{13}$ through facile wet chemistry under mild conditions. This phase transition process is novel since no such experiment is reported previously. Further experiments are then expected to confirm it. However, the amount of acid should be carefully controlled since $\mathrm{Na}_{2} \mathrm{Ti}_{6} \mathrm{O}_{13}$

$45 \mathrm{can}$ be further converted to $\mathrm{TiO}_{2}$ under acidic condition, as shown in the reaction (3).

\section{Conclusions}

In summary, the first principle DFT calculations have been performed to compare the physicochemical properties of Ti-O 50 based materials. Although they are all comprised of $\mathrm{TiO}_{6}$ octahedra, it is found that their physicochemical properties are much different. The layered $\mathrm{Na}_{2} \mathrm{Ti}_{3} \mathrm{O}_{7}$ shows highest chemical reactivity and largest bandgap energy. As a comparison, anatase $\mathrm{TiO}_{2}$ is chemically inert with the highest photoactivity. The 55 physicochemical properties of $\mathrm{Na}_{2} \mathrm{Ti}_{6} \mathrm{O}_{13}$ fall between those of anatase $\mathrm{TiO}_{2}$ and $\mathrm{Na}_{2} \mathrm{Ti}_{3} \mathrm{O}_{7}$. Meanwhile, our energetic analysis demonstrates that all Ti-O based materials are stable under the
pH-neutral solution. However, $\mathrm{TiO}_{2}$ is more stable under acidic condition while titanates are preferred in basic solutions. Our 60 theoretical results also predict that $\mathrm{Na}_{2} \mathrm{Ti}_{6} \mathrm{O}_{13}$ can be generated by the interaction between $\mathrm{Na}_{2} \mathrm{Ti}_{3} \mathrm{O}_{7}$ and weak acid, which proposes a novel way to produce sodium titanates with lower sodium content. According to our theoretical comparison, Ti-O based materials can therefore be pre-screened for their difference 65 applications.

\section{Acknowledgements}

We thank the Australian Research Council for funding. This research was undertaken on the National Computational Infrastructure (NCI) in Canberra, Australia, which is supported 70 by the Australian Commonwealth Government.

\section{Notes and references}

1. U. Diebold, Surf. Sci. Rep., 2003, 48, 53-229.

2. D. V. Bavykin, J. M. Friedrich and F. C. Walsh, Adv. Mater., 2006, 18, 2807-2824.

75 3. W. J. Zhou, H. Liu, R. I. Boughton, G. J. Du, J. J. Lin, J. Y. Wang and D. Liu, J. Mater. Chem., 2010, 20, 5993-6008.

4. D. Hennings, M. Klee and R. Waser, Adv. Mater., 1991, 3, 334-340.

5. A. Fujishima, X. T. Zhang and D. A. Tryk, Surf. Sci. Rep., 2008, 63, 515-582.

80 6. A. Fujishima and K. Honda, Nature, 1972, 238, 37-38.

7. H. J. Zhao, D. L. Jiang, S. Q. Zhang, K. Catterall and R. John, Anal. Chem., 2004, 76, 155-160.

8. D. V. Bavykin, A. A. Lapkin, P. K. Plucinski, J. M. Friedrich and F. C. Walsh, J. Phys. Chem. B, 2005, 109, 19422-19427.

85 9. K. Amine, I. Belharouak, Z. H. Chen, T. Tran, H. Yumoto, N. Ota, S. T. Myung and Y. K. Sun, Adv. Mater., 2010, 22, 3052-3057.

10. E. A. Behrens, P. Sylvester and A. Clearfield, Environ. Sci. Technol., 1998, 32, 101-107.

11. W. Zhang, L. D. Zou and L. Z. Wang, Appl. Catal. A-Gen., 2009, 371, 1-9.

12. H. Y. Jeong, J. Y. Lee and S. Y. Choi, Adv. Funct. Mater., 2010, 20, 3912-3917.

13. H. M. Zhang, Y. H. Han, X. L. Liu, P. R. Liu, H. Yu, S. Q. Zhang, X. D. Yao and H. J. Zhao, Chem. Commun., 2010, 46, 8395-8397.

95 14. M. Gratzel, Nature, 2001, 414, 338-344.

15. U. Bach, D. Lupo, P. Comte, J. E. Moser, F. Weissortel, J. Salbeck, H. Spreitzer and M. Gratzel, Nature, 1998, 395, 583-585.

16. K. S. Brammer, S. H. Oh, J. O. Gallagher and S. H. Jin, Nano Lett., 2008, 8, 786-793.

100 17. Y. Wang, H. M. Zhang, Y. H. Han, P. R. Liu, X. D. Yao and H. J. Zhao, Chem. Comm., 2011, 47, 2829-2831.

18. H. G. Yang, C. H. Sun, S. Z. Qiao, J. Zou, G. Liu, S. C. Smith, H. M. Cheng and G. Q. Lu, Nature, 2008, 453, 638-U634.

19. E. A. Carter, Science, 2008, 321, 800-803.

105 20. A. Vittadini, M. Casarin and A. Selloni, Theor. Chem. Acc., 2007, 117, 663-671.

21. A. Riss, M. J. Elser, J. Bernardi and O. Diwald, J. Am. Chem. Soc. 2009, 131, 6198-6206.

22. C. Y. Xu, Q. Zhang, H. Zhang, L. Zhen, J. Tang and L. C. Qin, J. 110 Am. Chem. Soc., 2005, 127, 11584-11585.

23. S. Zhang, Q. Chen and L. M. Peng, Phys. Rev. B, 2005, 71, 014104.

24. H. Zhang and H. Y. Wu, Phys. Status Solidi B-Basic Solid State Phys., 2008, 245, 37-43.

25. Y. Wang, H. W. Liu, H. M. Zhang, X. D. Yao and H. J. Zhao, Chem. Phys. Lett., 2011, 511, 82-86.

26. P. Giannozzi, S. Baroni, N. Bonini, M. Calandra, R. Car, C. Cavazzoni, D. Ceresoli, G. L. Chiarotti, M. Cococcioni, I. Dabo, A. Dal Corso, S. de Gironcoli, S. Fabris, G. Fratesi, R. Gebauer, U. Gerstmann, C. Gougoussis, A. Kokalj, M. Lazzeri, L. Martin-Samos, 120 N. Marzari, F. Mauri, R. Mazzarello, S. Paolini, A. Pasquarello, L. Paulatto, C. Sbraccia, S. Scandolo, G. Sclauzero, A. P. Seitsonen, A. Smogunov, P. Umari and R. M. Wentzcovitch, J. Phys.-Condes. Matter, 2009, 21, 95502-95502. 
27. D. Vanderbilt, Phys. Rev. B, 1990, 41, 7892.

28. J. P. Perdew, W. Burke and M. Ernzerhof, Phys. Rev. Lett., 1996, 77, 3865.

29. Y. Wang and G. S. Hwang, Surf. Sci., 2003, 542, 72-80.

5 30. H. W. Liu, D. J. Yang, Z. F. Zheng, X. B. Ke, E. Waclawik, H. Y. Zhu and R. L. Frost, J. Raman Spectrosc., 2010, 41, 1331-1337.

31. D. J. Yang, Z. F. Zheng, Y. Yuan, H. W. Liu, E. R. Waclawik, X. B. Ke, M. X. Xie and H. Y. Zhu, Phys. Chem. Chem. Phys., 2010, 12, 1271-1277.

10 32. H. Y. Zhu, Y. Lan, X. P. Gao, S. P. Ringer, Z. F. Zheng, D. Y. Song and J. C. Zhao, J. Am. Chem. Soc., 2005, 127, 6730-6736.

33. T. Inoue, A. Fujishima, S. Konishi and K. Honda, Nature, 1979, 277, 637-638.

34. Y. Inoue, T. Kubokawa and K. Sato, J. Chem. Soc.-Chem. Commun., 1990, 1298-1299.

35. X. K. Zhang, S. L. Tang, J. Y. Yu, L. Zhai, Y. G. Shi and Y. W. Du, Cryst. Growth Des., 2009, 9, 2971-2973.

36. R. Dominko, E. Baudrin, P. Umek, D. Arcon, M. Gaberscek and J. Jamnik, Electrochem. Commun., 2006, 8, 673-677.

20 37. R. Dominko, L. Dupont, M. Gaberscek, J. Jamnik and E. Baudrin, J. Power Sources, 2007, 174, 1172-1176.

38. P. Billik, M. Caplovicova and L. Caplovic, Mater. Res. Bull., 2010, $45,621-627$.

39. L. M. Torres-Martinez, I. Juarez-Ramirez, K. Del Angel-Sanchez, L.

25 Garza-Tovar, A. Cruz-Lopez and G. Del Angel, J. Sol-Gel Sci. Technol., 2008, 47, 158-164.

40. K. Teshima, S. Lee, S. Murakoshi, S. Suzuki, K. Yubuta, T. Shishido, M. Endo and S. Oishi, Eur. J. Inorg. Chem., 2010, 2936-2940.

41. K. Teshima, K. Yubuta, T. Shimodaira, T. Suzuki, M. Endo, T.

30 Shishido and S. Oishi, Cryst. Growth Des., 2008, 8, 465-469.

42. L. Zhen, C. Y. Xu, W. S. Wang, C. S. Lao and Q. Kuang, Appl. Surf. Sci., 2009, 255, 4149-4152.

43. A. E. Mattsson, R. Armiento, J. Paier, G. Kresse, J. M. Wills and T. R. Mattsson, J. Chem. Phys., 2008, 128, 84714-84714.

35 44. D. J. Yang, Z. F. Zheng, H. W. Liu, H. Y. Zhu, X. B. Ke, Y. Xu, D. Wu and Y. Sun, J. Phys. Chem. C, 2008, 112, 16275-16280.

45. D. J. Yang, Z. F. Zheng, H. Y. Zhu, H. W. Liu and X. P. Gao, Adv. Mater., 2008, 20, 2777-+.

46. X. M. Sun and Y. D. Li, Chem.-Eur. J., 2003, 9, 2229-2238.

40 47. A. L. Linsebigler, G. Q. Lu and J. T. Yates, Chem. Rev., 1995, 95, 735-758.

48. J. Wang, D. N. Tafen, J. P. Lewis, Z. L. Hong, A. Manivannan, M. J. Zhi, M. Li and N. Q. Wu, J. Am. Chem. Soc., 2009, 131, 1229012297.

45 49. C. S. Wang and W. E. Pickett, Phys. Rev. Lett., 1983, 51, 597-600.

50. C. J. Cramer and D. G. Truhlar, Phys. Chem. Chem. Phys., 2009, 11, 10757-10816.

51. F. Labat, P. Baranek, C. Domain, C. Minot and C. Adamo, J. Chem. Phys., 2007, 126, 12.

50 52. H. Tang, H. Berger, P. E. Schmid and F. Levy, Solid State Commun., 1994, 92, 267-271.

53. B. L. Wang, Q. Chen, R. H. Wang and L. M. Peng, Chem. Phys. Lett., 2003, 376, 726-731.

54. E. Morgado, M. A. S. de Abreu, O. R. C. Pravia, B. A. Marinkovic,

55 P. M. Jardim, F. C. Rizzo and A. S. Araujo, Solid State Sci., 2006, 8, 888-900. 